\title{
CONSCIENTIZATION BY RADIO IN TANZANIA
}

\section{Budd Hall*}

\section{Introduction}

This article is the first fruits of the evaluation of the Tanzanian education campaign, called 'Mtu Ni Afya' or 'Man is Health'. It reviews the genesis of the campaign, its objectives and organization, examples of the groups at work, preliminary findings and other significant aspects of the total effort.

Tanzania is unique in the Third World in terms of the attention and emphasis placed on adult or non-formal education for development purposes. One of the most exciting and promising projects to come out of this atmosphere has been a mass radio study group campaign, involving more than two million people.

The campaign made use of radio, newspapers, cheaply printed materials and other media to reach its participants in 75,000 organized study groups. The aim of the campaign was to make people aware about what they themselves could do to prevent five widespread diseases: malaria, tuberculosis, dysentry, hookworm and bilharzia. The groups listened to radio programmes, read or talked about printed materials and then discussed the more important questions of whether or not anyone in the group had ever suffered from any of the symptoms discussed, whether the group felt the discussion of the disease to be important in their community, and what the members together should do about preventing the disease.

\section{Origin of the Idea}

The health education campaign did not originate from the health or medical profession in Tanzania, but from adult educators. Nevertheless, the health education unit of the Ministry of Health came in on the

\footnotetext{
* Budd Hall is a Visiting Fellow (June 1974-June 1975) at the Institute of Development Studies. From 1972-74 he was Senior Research Fellow at the Institute of Adult Education, Dar es Salaam.

1 Based on research undertaken with financial support from the Swedish International Development Authority and the International Council for Adult Education.
} 
campaign at a very early stage, as did the rural development division, TANU (the political party) and the Ministry of National Education. The idea grew out of a combination of experiences beginning with three small scale radio study group projects on political themes which the Institute of Adult Education at the University of Dar es Salaam conducted in 1969, 1970 and 1971. During these earlier projects it became clear that this group learning approach was practical, popular and promising.

To this experience on a limited scale was added some of the thinking which had come from the Brazilian and Chilean experience with literacy as a consciousness raising experience. In the context of health education, this meant that people might be able, through discussion, to raise their own levels of consciousness about why they become ill and to realise that they have power themselves to prevent the most common diseases. The assumptions for this to take place are that all the persons in the group are equals in learning, including the group leader. In practice, this means that the group leader is not trained in matters related to the prevention of disease, but only in group discussion methods, matters related to the materials of the campaign, and sources for assistance, if necessary.

The most significant influence on the campargn came from the policies of TANU and the government. Tanzania's development strategy depends on at least three principles: rural areas are to be given priority in planning decisions as 95 per cent of the population live there; if development is to benefit the people, the people must participate in the planning of that development; and development is most effective in the long run when carried out by collective, not individual, efforts. For adult educators the message is clear. Programmes are organized which provide for rural areas, and which at the same time stimulate the participation of people in decisions concerned with their own development.

This still does not answer the question why health education was selected for the campaign. In the first place health education of any kind was difficult to find in many parts of Tanzania. Second, it was learned that the most common diseases in Tanzania were those which could be prevented by group, if not individual, actions, such as building 
latrines or improving water sources. Thirdly, it was felt that a cycle existed of poor health $=$ low work output $=$ poor crops $=$ poor nutrition = poor health, and that, however oversimplified this notion was, a national campaign of prevention was an important step in breaking it. Lastly, there was concern that many people were moving to villages for the first time as part of rural collectivization and that this introduced an increased danger of spread of disease. At the same time, the formation of ujamaa villages could be seen as a unique opportunity for organized health education and action.

Aims and Organization of the Campaign

The campaign had three objectives:

1. to increase participants' awareness of and to encourage group actions on measures which groups and individuals can take to make their lives healthier;

2. to provide information about the symptoms and prevention of specific diseases;

3. for those who had participated in the national literacy campaign, to encourage the maintenance of newly acquired reading skills by providing suitable follow-up material.

Two elements were fundamental to the fulfilment of these objectives: First, that pre-existing structures were available to implement the plans; second, that the planning was not rushed, and was thoroughly systematic.

Tanzania has built a widespread adult education network under the administration of the Ministry of National Education. It is composed of nearly 2,000 national, regional, district and divisional adult education co-ordinators and supervisors. These personnel are responsible to the thousands of adult education centres which operate using primary schools as bases. They are paralleled by a network of health education officers. Both sets of personnel were largely responsible for the day to day operation of the campaign, from the training of group leaders to encouragement during the broadcasting. They were supplemented by the networks of TANU and the Rural Development Division.

The planning for the campaign began 18 months before the first radio broadcast went on the air and was carried out under the guidance of a 
national co-ordinating committee which met as often as weekly during the more intense planning periods. This committee ensured that from the beginning as many agencies as were necessary to the success of the campaign were involved. A mass campaign at rural level cannot be carried out by the activities of only one sector or one agency: it requires the co-ordinated efforts of all agencies working in the rural areas. At village level, the adult education personnel worked with the rural development extension officers, the local TANU officials and the health education personnel in organizing groups before the campaign, and in giving the groups support once the radio programmes were under way.

The Staged Training System

Experience from the earlier radio study group campaigns indicated that a trained study group leader was essential to successful group activity. One of the most important reasons for training group leaders is to convey the message that group leaders are not teachers. A leader does not tell the group what to do or how to do it, but is trained to guide group studies, to understand that he is only 'first among equals'. He must be trained in tact: to encourage the withdrawn, subdue the over-dominant and generally stimulate full participation. It is equally important to provide suggestions to leaders on how to move from discussion to action in the groups.

Logistically, the Tanzanian scheme required 75,000 study group leaders to be trained in $3 \frac{1}{2}$ months. This was done by means of a staged training system whereby regional teams trained district teams who in turn trained the study group leaders at divisional level. There were seven regional seminars for 200 participants (30 per seminar); 61 district level seminars for 1,400 participants (25 per seminar); and 2,000 divisional seminars for roughly 75,000 study groups leaders (37 per seminar). All the seminars lasted from two to three days.

An important lesson from this experience of mass training is that it is possible to ensure that the central elements of the training message survive the diffusion process from the first to the last stages. That is, no vital element need be damaged by dilution. This is one of the most crucial aspects in the development of a mass campaign. In the Tanzanian case, the key elements of the training message were 
maintained by several devices: centrally prepared handouts (duplicated locally); the use of prepared flip-over charts summarizing the most important points of training; pre-recorded cassettes of simulated radio programmes for role-playing experience; and copies of the actual materials to be used in the campaign.

\section{The Groups in Action}

The pattern which was most often followed by groups during the campaign was as follows:

1. assemble - the radio plays music related to the campaign, political songs, poems and short announcements;

2. the group members listen to the 20 -minute radio programme;

3. the group leader or someone in the group who can, reads aloud the appropriate section of the text;

4. discussion begins first with the question of the relevance of the material presented to the actual circumstances of the group's members;

5. discussion takes place about various persons' experience with the disease, alternative causes of the disease and possible ways of preventing it;

6. resolutions are made and agreed upon by the group for specific actions which could be implemented in the village;

7. during the ensuing week - before the next programme - the resolutions are carried out by the group members and, most likely, others in the village.

A major difference between this campaign and previous attempts was the importance placed on action following discussion. The types of activities which individual groups undertook varied in different areas. In a survey of 213 groups, it was found that clearing vegetation from around the homes was carried out by 28 per cent of the groups, digging, repairing or rebuilding latrines by 20 per cent, destroying areas of stagnant water by 24 per cent, boiling water by 12 per cent, and cleaning the area around water supplies by 11 per cent. In one district (Dodoma), about 200,000 latrines were built during the campaign period. The result at the end of the campaign was that not a single house was without a latrine. This occurred in an area where colonial officers had tried to enforce latrine construction nearly 50 years previously with dismal results and much rancour. In one division in 
Iringa the people decided that having a latrine for each home was not enough. What, for example, could travellers use, while waiting on the side of the road for buses? The solution was obviously more latrines. It was agreed accordingly that one latrine would be built at each major bus stop in the area.

\section{Attendance}

The national average attendance figure for the campaign was 63 per cent. That is, at any given session anywhere during the campaign, some 63 per cent of those enrolled were probably in attendance. This figure can only be meaningful when compared with the average attendance at other forms of rural adult education such as literacy or political education classes. The Ministry of National Education estimates that actual attendance at any given session for the nearly three million persons enrolled in adult education classes is about 33 per cent. The literacy project estimated between 25-40 per cent attendances per session. This means that the attendance figures for the short term campaign were quite satisfactory.

figure 1 Attendance by week - all regions combined

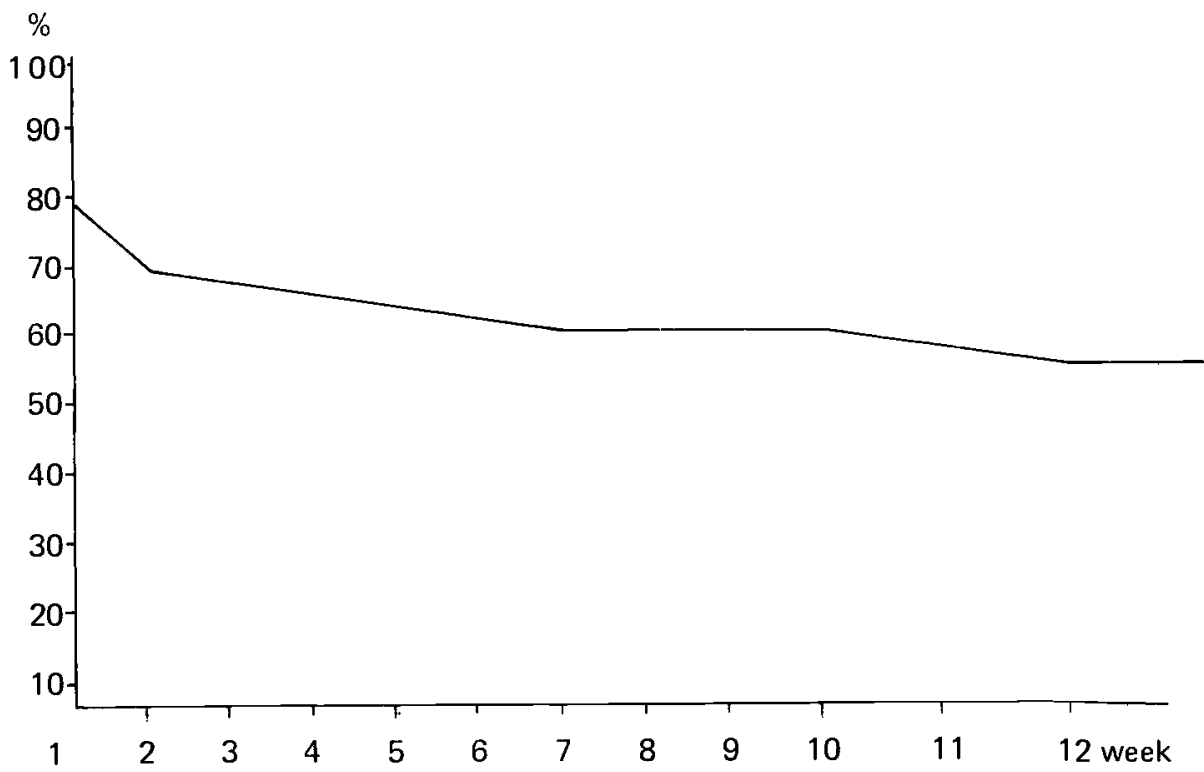


The graph above indicates the attendance pattern week by week. Several points are made. First it can be seen that even for the first meeting over 20 per cent of those enrolled failed to show up. If the attendance figures were adjusted to include those who enrolled but never actually attended a session, the average attendance would rise to almost 83 per cent. The second point that emerges is that attendance during the main part of the campaign was quite steady! The change between the second and the tenth week was only about 5 percentage points.

\section{Evaluation of the Campaign}

Built into the campaign from the beginning was a series of measurements and sources of information designed to aid in its assessment. In addition to such routine aspects as total enrolment, national distribution of groups and attendance rates, the evaluation design provided for the measurement of the amount of information gained through this method of study, and of the change in observable household health practices as a result.

In examining the data from the control groups, we begin to run into some difficulties. Perhaps the biggest difficulty in selecting a control group during a campaign of this type is in finding a group of people in an intensive campaign designed to mobilise everyone which has not taken part in the campaign in some way. In Mafia for example, no control groups were chosen because it was said that in a national campaign of this sort all people had a right to participate in the health education. In Newala the situation was similarly difficult as those in the control group were swept into the excitement of the campaign along with the other adult education students and began to study the material on their own. The result in this case was that the control group actually scored higher than the Mtu ni Afya groups.

Nevertheless, the mean score of the Mtu ni Afya groups increased by 20 per cent from the pre-test to the post-test, an increase from 43 per cent to 63 per cent. The control groups taken together scored a 15 per cent gain from 43 per cent to 58 per cent. The Mtu ni Afya groups scored 5 per cent higher than the control groups, but this difference was not found to be statistically significant. Only when the scores from the energetic Mtwara control group are removed are the differences 
statistically significant. If the control group in Mtwara is excluded the remaining control groups show an increase of 9 per cent compared with the 20 per cent of all others. This difference is statistically significant.

\section{Changes in Health Practices}

Of particular importance to the campaign was the measurement of change in health practices. In a survey done of eight villages before and after the campaign a series of 11 observable health practices, such as the presence of a latrine, the use of the latrine, absence of broken pots and pools of stagnant water combined as a health practices index. Each household was surveyed and could score between 0 and 11 depending on the number of positive practices observed. Before the campaign the mean health practices index for all houses in the eight villages $(2,084)$ was 3.0 or three out of eleven positive observed health practices. After the campaign the mean index was 4.8 , a 15 per cent gain. The largest element in raising these scores were the digging and construction of pit latrines and clearing vegetation from the immediate vicinity of the house.

The final evaluaton of any health education campaign must lie in the reduction of the incidence of disease. Provisions for the measurement of the reduction of disease level was not provided in the evaluation of this campaign, as the isolation of the multiple factors associated with good health would have proved impossible, given the nature of the campaign and the records available. There have been reports of a large increase in the number of people attending rural dispensaries in many areas. There is proof that large numbers of people participated in the campaign; that people learned from this method and that literally millions of hours were put into environmental changes as a result of the campaign.

\section{Finance}

The campaign was supported by a capital grant from the Swedish International Development Authority of $\$ 210,000^{2}$. Of this capital, training accounted for roughly 36 per cent, printing of study materials 50 per cent, distribution another 6 per cent and radio production and

2 The government of Tanzania's allocation to the Ministry of National Education for related activities in Adult Education in 1974/75 was \$7,044,000.

102 
research the remaining 8 per cent. The actual production of the radio programme cost less than $\$ 600$ additional capital. This is because production of the radio programmes made use of the already existing broadcast and radio facilities at Radio Tanzania and of the services of health education and adult education broadcasters whose work was covered in salaries already being paid by their respective institutions. What this means is that the campaign was able to reach participants at an additional cost of roughly $\$ 0.10$ per person enrolled. This compares with about $\$ 3.00$ in 1972 per adult evening class student for 20 hours tuition per term.

\section{Conclusion}

It seems clear that the Tanzanian large scale conscientization campaign in health education is one of the most interesting education projects to have taken place in Africa in recent years. Some of the most significant aspects and reasons why the campaign deserves very close study by those concerned with development, particularly rural development, are given below.

1. An atmosphere has been created in which people have been able to take some control of their own health. It has been all too common for people in rural areas to see illness as being related to factors outside their control, or as caused by sociological difficulties in the commiunity. Where the possibility of help has been recognized, it is seen too much in terms of modern medicine, the provision of which is hopelessly inadequate in rural Tanzania. This campaign has shown that radio and other media can be used to raise people's awareness that they themselves have control over many common health problems and that groups of people working together can change many of the least healthy aspects of the village environment;

2. large numbers of the rural population have been given access to specific and relevant information. The rural population makes up the bulk of people living in Tanzania, as in most Third World nations. This campaign has shown itself to be very effective in reaching a very large portion of the rural population which has in the past not had access to more formal types of education because of high costs, shortsightedness in planning or simply different priorities;

3 We assume that the normal work of those and other personnel continued normally, so that no opportunity costs were incurred. 
3. the methods offer a realistic alternative to much criticized 'traditional' student-teacher relationships. The shortcomings of traditional student-teacher relationships have been criticized frequently by people such as Ivan Illich and Paulo Freire. It is clear that an educational setting for adults who are to direct their own development cannot rely on methods whereby one person is seen as an 'expert' or teacher and possesses all knowledge and others simply as recipients of knowledge. The emphasis in the new approach is on complete and equal participation by the group members: they actively explore the relevance of the information to the reality of their own lives. 'This joint exploration creates a live understanding of a personal situation for each one involved and becomes a strong motivating element for improving community life;

4. costs per participant are low. The campaign, by making use of a network of already existing extension officers and primary schools in combination with the use of radio programmes and mass produced printed materials, was able to operate for about $\$ 0.10$ per group member. This is an example of the large savings which can be made through a careful orchestration of mass media, mass organization and small groups. With smaller numbers of participants the costs are higher, but still attractive. The campaign in 1971 which reached about 20,000 participants cost $\$ 0.56$ per person;

5. grass-roots political structures were strengthened. The campaign was a co-operative effort by several ministries and the political party, TANU. In areas such as Dodoma or Mtwara where the campaign was very en thusiastically received, the study group leaders were often the ten-house cell leaders of the party. The effect of this was to provide an opportunity for the ten-house cell units to have the kind of participation in local decision-making which Tanzania is depending on: people's participation in their own development, and development with the people not for the people;

6. the mobilization of large numbers of people necessitates an extensive administrative and communication network. The lesson of this campaign, however, is that it is possible to use already existing structures such as agricultural or community development extension systems, providing these personnel are given some training in the new methods;

7. a centrally planned campaign has some dangers. There are always dangers in a centrally planned campaign that the educational content 
will be seen by both the planners and the people themselves as something which is not to be questioned, merely acted upon. There are many examples of health and family planning campaigns which merely pump the message into the heads of the people and expect results. Experience from the 'Man is Health' campaign indicates that the number of campaigns which can be effectively done on a national level may be limited. The information which is presented needs to be of such universal concern to those taking part, as to stimulate their own analysis and thereby act in ways appropriate to specific local situations. There may not be many subjects which can be universally applicable, but there is no reason why these same approaches could not be used at a regional or even smaller level;

8. an effective mass campaign in rural areas needs the co-ordinated efforts of all the agencies and ministries concerned. Without the co-ordinated effort of rural development officers, health education officers, adult education officers and some voluntary agencies this campaign would have been much less success ful. Good health depends on more than the attention of the health officers. It means consciousness raising, assistance with construction skills, even increased community production in order to have the necessary cash to buy such items as window netting or malaria tablets. Effective rural development of any kind needs a frontal approach rather than a single sector approach.

As the study of the campaign continues it is hoped that the more detailed examination of factors contributing to the success of the campaign can be isolated. It is also hoped that some of the most important factors in planning similar campaigns can be indicated. 